\title{
POLYMORPHISM OF THE TMPRSS2 GENE RELATING TO COVID-19 SUSCEPTIBILITY IN VIETNAMESE POPULATION
}

\author{
Nguyen Dang Ton ${ }^{1,2}$, Vu Phuong Nhung ${ }^{1}$, Duong Thu Trang ${ }^{1}$, Nguyen Thi Thanh Hoa ${ }^{1}$, \\ Nguyen Hoai Nam ${ }^{1}$, Hoang Thi Thuan ${ }^{2}$, Ho Anh Son ${ }^{3}$, Nguyen Thi Thanh Hai ${ }^{4,5}$, \\ Pham Ngoc Thach ${ }^{4}$, Nong Van Hai ${ }^{1,2}$, Nguyen Hai Ha, ${ }^{1,2, *}$ \\ ${ }^{1}$ Institute of Genome Research, VAST, Vietnam \\ ${ }^{2}$ Graduate University of Science and Technology, VAST, Vietnam \\ ${ }^{3}$ Vietnam Military Medical University, Ha Noi, Vietnam \\ ${ }^{4}$ National Hospital for Tropical Diseases, Ha Noi, Vietnam \\ ${ }^{5}$ Hanoi Medical University, Ha Noi, Vietnam \\ Received 12 December 2020, accepted 16 March 2021
}

\begin{abstract}
Recently, a contagious lung disease named coronavirus disease 2019 (COVID-19) caused by severe acute respiratory syndrome coronavirus 2 (SARS-CoV-2), rapidly spread worldwide and has many serious consequences for human health. Human genetic polymorphisms may contribute to the variation of incidence, mortality as well as severity of COVID-19. To date, this factor in the Vietnamese population remains unknown. A cellular protease termed transmembrane protease serine 2 (TMPRSS2) was found to play a vital role in the entry of SARS-CoV-2 into host cells. In this study, we investigated polymorphisms in the TMPRSS 2 gene from 270 whole exome sequencing data of Vietnamese peoples. We also employed bioinformatics tools including SIFT, Polyphen-2, and PROVEAN to predict the possible function of missense variants. A total of 34 TMPRSS2 variants were identified, of which, 29 were in non-coding regions and 14 were in coding regions. Variants found in exons included seven synonymous and seven non-synonymous point mutations, one of which was novel mutation (c.A1336C/p.R446R). Mutation c.G589A/p.V197M (rs12329760) possesses the highest frequency and was predicted to have the ability to damage protein by SIFT and Polyphen-2. In addition, the damaging possibility was also found in c.T244G/p.Y82D and c.C896T/p.A299V variants. This study contributes to the understanding of Vietnamese genetic variation databases relating to susceptibility to COVID-19.
\end{abstract}

Keywords: SARS-CoV-2, human TMPRSS2, genetic polymorphism.

Citation: Nguyen Dang Ton, Vu Phuong Nhung, Duong Thu Trang, Nguyen Thi Thanh Hoa, Nguyen Hoai Nam, Hoang Thi Thuan, Ho Anh Son, Nguyen Thi Thanh Hai, Pham Ngoc Thach, Nong Van Hai, Nguyen Hai Ha, 2021. Polymorphism of the TMPRSS2 gene relating to COVID-19 susceptibility in Vietnamese population. Academia Journal of Biology, 43(1): 119-128. https://doi.org/10.15625/2615-9023/15829

*Corresponding author email: nguyenhaiha@igr.ac.vn

(C2021 Vietnam Academy of Science and Technology (VAST) 


\section{INTRODUCTION}

Late December 2019, a novel betacoronavirus designated as severe acute respiratory syndrome coronavirus 2 (SARSCoV-2) (Gorbalenya et al., 2020) was detected to be the etiologic agent of a new viral pneumonia emerging in Wuhan city, Hubei Province, China (Zhu et al., 2020; Wang et al., 2020). Consequently, the transmission occurred from person to person (Chan et al., 2020; Dong et al., 2020) and this lung disease, then termed severe coronavirus disease 2019 (COVID-19) by World Health Organization (WHO), rapidly spread worldwide. As of 4 December 2020, there were approximately 63.9 million confirmed cases and 1.4 million deaths recorded during COVID-19 epidemic (WHO, 2020). SARSCoV-2 entry is driven by binding of the viral spike (S) proteins to the peptidase angiotensin-converting enzyme 2 (ACE2), spike cleavage mediated by Furin, and $\mathrm{S}$ protein priming by a cellular protease named transmembrane protease serine 2 (TMPRSS2) (Li et al., 2003; Kuhn et al., 2004; Hoffmann et al., 2020; Walls et al., 2020; Wu et al., 2020). SARS-CoV-2 infection therefore depends on the expression of ACE2, TMPRSS 2 and Furin.

Incidence and mortality of COVID-19 pandemic vary worldwide based on multiple factors such as age, race, ethnicity and health condition. For example, diabetes, hypertension and cardiovascular disease were indicated as being risk factors for severity and mortality in people infected with SARS-CoV2 (De Almeida-Pititto et al., 2020). An assessment of the influence of COVID-19 among American Indian and Alaska Native in 23 States conducted by Hatcher and his colleages highlighted that the incidence rate for this population was 3.5 times higher than that for non-Hispanic white persons (Hatcher et al., 2020). Furthermore, another evaluation of COVID-19 impact variation across States of America and New York City also showed disparities in death rates associated with race, ethnicity and age (Gross et al., 2020). In these States, both the Black and Latinx experienced a significant higher risk of mortality than the White population.

Apart from environmental factors, health conditions and methods for prevention, genetic susceptibility may be a reasonable explanation for not only race- and ethnicitystratified COVID-19 incidence and mortality, but also disease severity. Indeed, polymorphisms in genes responsible for SARS-CoV-2 entry such as ACE2 and TMPRSS2 play a causative role in variable transmissibility and disease progression among patients (Hou et al., 2020; Baughn et al., 2020). However, the genetic polymorphisms of these genes in the Vietnamese population have not been reported to date. Since the ACE2 gene showed a low level of polymorphism in recent reports (Torre-Fuentes et al., 2020), the current study concentrated on the higher polymorphic TMPRSS2, to enhance understanding of this gene in the Vietnamese population and its association with virus diseases in further studies. In summary, we identified all genetic variants of TMPRSS 2 in 270 whole exome sequencing (WES) data of Vietnamese people. Furthermore, we used bioinformatics tools including SIFT, Polyphen-2 and PROVEAN to predict the possible functions of missense variants.

\section{MATERIALS AND METHODS}

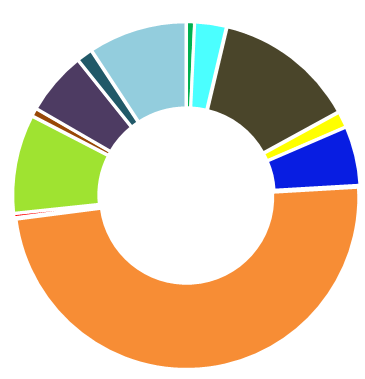

$$
\begin{aligned}
& \text { - Blood } \\
& \text { " Cadiovascular } \\
& \text { - Eyes } \\
& \text { " Ear, Nose and Throat } \\
& \text { - Metabolic } \\
& \text { - Neurological } \\
& \text { - Respiratory } \\
& \text { - Skin } \\
& \text { - Reproductive } \\
& \text { - Muscular/Skeletal } \\
& \text { - Multiple Congenital Anomalies } \\
& \text { " Normal }
\end{aligned}
$$

Figure 1. Distribution of subjects based on health condition

Our study was conducted using available WES data of 270 Vietnamese subjects. The data were collected and stored by the Institute of Genome Research from 2018 to 2020. This group comprises healthy people and patients 
with diseases related to blood, cardiovascular system, eyes, ear, nose and throat, metabolism, neurological system, respiratory system, skin, reproductive system, muscular/skeletal and multiple congenital anomalies. Patients with Parkinson's disease of neurological group made up the highest proportion of subjects in this study.

\section{Whole exome sequencing}

For WES, library construction was performed by Sure Select V6-Post using the manufacturer's protocol (Agilent Technologies, Santa Clara, California, USA). The sequencing library is prepared by random fragmentation of DNA, following by 5' and 3' adapter ligation. Fragments ligated to adapter were subsequently amplified by PCR and gel purified. Enriched library was quantified using Qubit dsDNA HS Assay Kit (Thermo Fisher Scientific, Waltham, Massachusetts, USA). DNA fragments distribution was confirmed by 2100 Bioanalyzers using High sensitivity DNA chip (Agilent Technologies, Santa Clara, California, USA) with an expected size range from $200 \mathrm{bp}$ to $400 \mathrm{bp}$. Paired-end sequencing was conducted on the NovaSeq platform (Illumina, San Diego, California, USA) following the manufacturer's instructions. The mean exome coverage was more than $100 \mathrm{X}$ and each target base had at least 20X coverage.

\section{WES data analysis}

BWA (ver 0.7.10) was used to align raw sequence to the UCSC Human Reference Genome hg19. Single nucleotide polymorphisms (SNPs) and insertions/deletions (Indels) were detected by GATK (ver 3.6) and SAMtools variant caller (ver 1.8). Removing duplicate sequence reads was performed by Markduplicates in the Picard package. A self-designed tool was used to collect profiles of all TMPRSS2 variants detected from WES data of 270 subjects.

\section{Sorting intolerant from tolerant (SIFT)}

SIFT is a popular bioinformatics tool used to predict the ability of amino acid substitutions as well as non-synonymous polymorphisms to affect the function of proteins based on sequence homology and physical properties of amino acids (https://sift.bii.a-star.edu.sg/). SIFT output is based on the scores that range from 0.0 to 1.0. The substitutions with scores less than 0.05 and with scores greater than or equal to 0.05 are considered to be damaging and tolerated, respectively.

\section{Polymorphism phenotyping v2 (Polyphen-2)}

Polyphen-2 is a bioinformatics tool that predicts whether amino acid substitutions have impacts on protein structure and function (http://genetics.bwh.harvard.edu/pph2/).

Polyphen-2 result depends on the scores ranging from 0.0 to 1.0 . Variants with scores in the range from 0.0 to 0.15 , from 0.15 to 1.0 and from 0.85 to 1.0 are predicted to be benign, possibly damaging and damaging, respectively.

\section{Protein variation effect analyzer (PROVEAN)}

PROVEAN is a software tool that predicts the possible effects of protein sequence variations, including amino acid substitutions and indels on the biological function of proteins (http://provean.jcvi.org/index.php). PROVEAN score threshold is set at -2.5 . Variants with scores equal to or below -2.5 and with scores above -2.5 are predicted to be deleterious and neutral, respectively.

\section{RESULTS}

\section{Genetic variants of TMPRSS 2 in the coding region}

All coding variants of TMPRSS2 detected in 270 Vietnamese subjects are shown in table 1. Variant identification relied on the nucleotide reference sequence NM_001135099. Totally, 14 variants were found in the coding region of TMPRSS2, comprising 7 synonymous SNPs: c.C192G, c.C222T, c.A336G, c.C888T, c.T879C, c.G1203A, c.A1336C and 7 non-synonymous SNPs: c.G23T, c.T209C, c.T244G, c.G589A, c.G634A, c.C896T, c.G1568A. Out of 14 variants, one was novel mutation (c.A1336C, p.R446R) which has not been reported in all public databases. Variants with the highest 
frequencies are c.G589A (0.36296), c.C888T (0.26296) and c.A336G (0.20185) (Table 1).

As indicated in Figure 2, synonymous mutations were found mainly in Trypsin and Scavenger receptor cysteine-rich (SRCR)-like domain (p.I293I, p.G296G, p.V401V,
p.R446R) and domains of unknown function (p.P64P, p.Y74Y, p.T112T). Nonsynonymous variants are located in Trypsin domain (A299V, R523Q), SRCR-like domain (V197M, D212N) and domains of unknown function (G8V, V70A, Y82D).

Table 1. Variants of TMPRSS2 in the coding region.

\begin{tabular}{|c|c|c|c|c|c|c|c|c|}
\hline \multirow[t]{2}{*}{ Exon } & \multirow{2}{*}{$\begin{array}{l}\text { Location on } \\
\text { chromosome }\end{array}$} & \multirow{2}{*}{$\begin{array}{l}\text { Reference } \\
\text { SNP ID }\end{array}$} & \multirow{2}{*}{$\begin{array}{l}\text { Nucleotide } \\
\text { change }^{(*)}\end{array}$} & \multirow{2}{*}{$\begin{array}{l}\text { Amino acid } \\
\text { change }^{(*)}\end{array}$} & \multirow[t]{2}{*}{$\underset{(* *)}{\text { Frequency }}$} & \multirow{2}{*}{$\begin{array}{l}\text { Frequency } \\
\text { in this study }\end{array}$} & \multicolumn{2}{|c|}{$\begin{array}{l}\text { Number of } \\
\text { subjects }\end{array}$} \\
\hline & & & & & & & Het & Hom \\
\hline Exon 1 & chr21: 42879909 & rs 75603675 & c.G23T & p.G8V & 0.24381 & 0.02407 & 13 & 0 \\
\hline \multirow[t]{5}{*}{ Exon 3} & chr 21: 42866440 & rs141685390 & c.C192G & p.P64P & 0.00060 & 0.00370 & 2 & 0 \\
\hline & chr 21: 42866410 & rs187460831 & c.C222T & p.Y74Y & 0.00020 & 0.00185 & 1 & 0 \\
\hline & chr 21: 42866423 & rs201093031 & c.T209C & p.V70A & 0.00060 & 0.00370 & 2 & 0 \\
\hline & chr 21: 42866388 & rs201679623 & c.T244G & p.Y82D & 0.00100 & 0.01296 & 7 & 0 \\
\hline & chr 21: 42866296 & rs3787950 & c.A336G & p.T112T & 0.16294 & 0.20185 & 91 & 9 \\
\hline \multirow[t]{2}{*}{ Exon 6} & chr 21: 42852497 & rs 12329760 & c.G589A & p.V197M & 0.26138 & 0.36296 & 124 & 36 \\
\hline & chr 21: 42852452 & rs748571451 & c.G634A & p.D212N & Unknown & 0.00741 & 4 & 0 \\
\hline \multirow[t]{3}{*}{ Exon 9} & chr 21: 42845366 & rs150445636 & c.C896T & p.A299V & 0.00040 & 0.00185 & 1 & 0 \\
\hline & chr 21: 42845374 & rs2298659 & c.C888T & p.G296G & 0.20947 & 0.26296 & 102 & 20 \\
\hline & chr 21: 42845383 & rs 17854725 & c.T879C & p.I293I & 0.36621 & 0.11111 & 52 & 4 \\
\hline Exon 11 & chr 21: 42842654 & rs140121827 & c.G1203A & p.V401V & 0.00060 & 0.00185 & 1 & 0 \\
\hline Exon 12 & chr 21: 42840412 & novel & c.A1336C & p.R446R & Unknown & 0.00185 & 1 & 0 \\
\hline Exon 13 & chr 21: 42839671 & rs572530227 & c.G1568A & p.R523Q & 0.00020 & 0.00185 & 1 & 0 \\
\hline
\end{tabular}

Notes: (*) NM_001135099; (**) Frequency in "The 1000 genomes project 2015"; Hom: Homozygous; Het: Heterozygous.

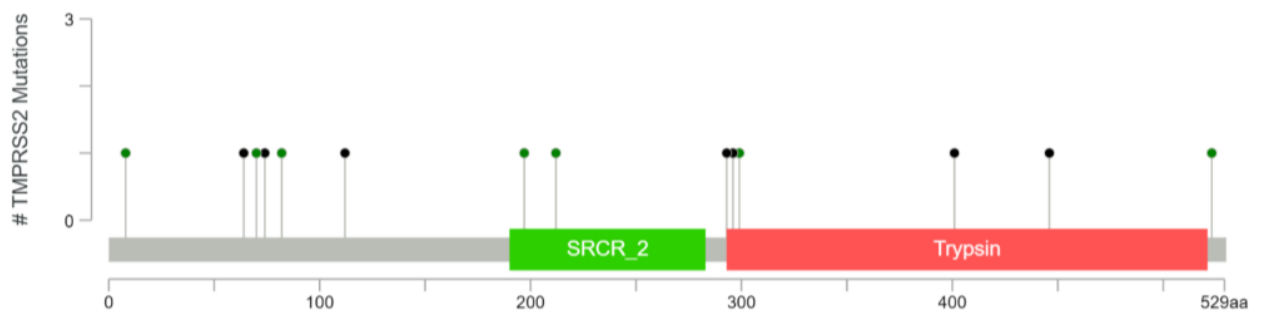

Figure 2. Distribution of TMPRSS2 mutations mapped by cBioPortal for Cancer Genomics.

Black: synonymous mutation, green: non-synonymous mutation

Schematic structures and properties of amino acid substitutions are shown in Table 2. The hydrophobicity-value are based on the hydrophobicity scale of Kyte and Doolittle (Kyte \& Doolittle, 1982). The greater the values, the more hydrophobic the amino acids. Except for p.G8V and p.A299V that pertain to more hydrophobic mutant residues, most variants result in equal or less hydrophobic mutant amino acids in comparison to the wild-type one. The charge of each amino acid is characterized by the isoelectric point $(\mathrm{pI})$, which is the $\mathrm{pH}$ at which the molecule is electrically neutral. There is no change in molecule's charge of 4 out of 7 amino acid replacements, including p.G8V, p.V70A, p.V197M and p.A299V. On the other hand, p.Y82D, p.D212N and p.R523Q lead to neutral-to-negative, negative-to-neutral and positive-to-neutral amino acid substitutions, respectively. The differences in molecular size are found in 6 substitutions. Of which, three mutants (p.G8V, p.V197M, p.A299V) are bigger and three mutants (p.V70A, p.Y82D, p.R523Q) are smaller than the wild-type residues. 
Polymorphism of the TMPRSS2 gene

Table 2. Schematic structures and properties of amino acid substitutions.

\begin{tabular}{|c|c|c|c|c|c|c|c|}
\hline \multirow{2}{*}{$\begin{array}{c}\text { Amino acid } \\
\text { substitution }\end{array}$} & $\begin{array}{c}\text { Schematic } \\
\text { structures }\end{array}$ & $\begin{array}{c}\text { Wydrophobicity-value } \\
\text { (Kyte \& Doolittle, 1982) }\end{array}$ & $\begin{array}{c}\text { Charge } \\
\text { (according to pI) }\end{array}$ & $\begin{array}{c}\text { Schematic } \\
\text { structures }\end{array}$ & $\begin{array}{c}\text { Hydrophobicity-value } \\
\text { (Kyte \& Doolittle, 1982) }\end{array}$ & $\begin{array}{c}\text { Charge } \\
\text { (according to pI) }\end{array}$ & $\begin{array}{c}\text { Size } \\
\text { Neutral }\end{array}$ \\
\hline p.G8V & -0.4 & Neutral & 4.2 & Mutant is \\
bigger
\end{tabular}


Functional prediction of variants using SIFT, Polyphen-2 and Mutation Taster

SIFT, Polyphen-2 and Mutation Taster were employed to evaluate possible effects of non-synonymous mutations in our study (Table 3). These three predictions might pave the way to investigate the possibility and extent of the missense variants to damage the protein. It is noteworthy that 3 mutations were predicted to exert deleterious effects on protein function by 2 out of 3 models. In particular, damaging abilities of p.Y82D and p.A299V were shown by Polyphen-2 and PROVEAN, while that of p.V197M was reported by SIFT and Polyphen-2. The remains were benign, neutral, possibly damaging or tolerated.

Table 3. Prediction of functional effects of TMPRSS2 variants.

\begin{tabular}{|c|c|c|c|c|}
\hline \multirow{2}{*}{ Variants } & \multirow{2}{*}{ Functional domain of protein } & \multicolumn{3}{|c|}{ Function prediction } \\
\cline { 3 - 5 } & & SIFT & Polyphen-2 & PROVEAN \\
\hline p.G8V & - & $\mathrm{T}$ & $\mathrm{P}$ & $\mathrm{N}$ \\
\hline p.V70A & - & $\mathrm{T}$ & $\mathrm{B}$ & $\mathrm{N}$ \\
\hline p.Y82D & - & $\mathrm{T}$ & $\mathrm{D}$ & $\mathrm{D}$ \\
\hline p.V197M & SRCR-like domain & $\mathrm{D}$ & $\mathrm{D}$ & $\mathrm{T}$ \\
\hline p.D212N & SRCR-like domain & $\mathrm{T}$ & $\mathrm{B}$ & $\mathrm{N}$ \\
\hline p.A299V & Serine proteases, trypsin domain & $\mathrm{T}$ & $\mathrm{D}$ & $\mathrm{D}$ \\
\hline p.R523Q & Serine proteases, trypsin domain & $\mathrm{T}$ & $\mathrm{B}$ & $\mathrm{N}$ \\
\hline
\end{tabular}

Notes: B: Benign; D: Damaging; N: Neutral; P: Possibly damaging; T: Tolerated, “-”: unknown.

The results of Polyphen-2 prediction of p.V197M variant were shown in Figure 3. In Polyphen-2 prediction models, a combination of two pairs of datasets, including HumDiv and HumVar was used to test. HumDiv trained Polyphen-2 model prediction pointed out that it is probably damaging with a score of 0.997. Similarly, Humvar prediction also denoted that it is probably damaging with a score of 0.937 . Hence, this result leads to the ability that c.G589A mutation might alter the function of protein.

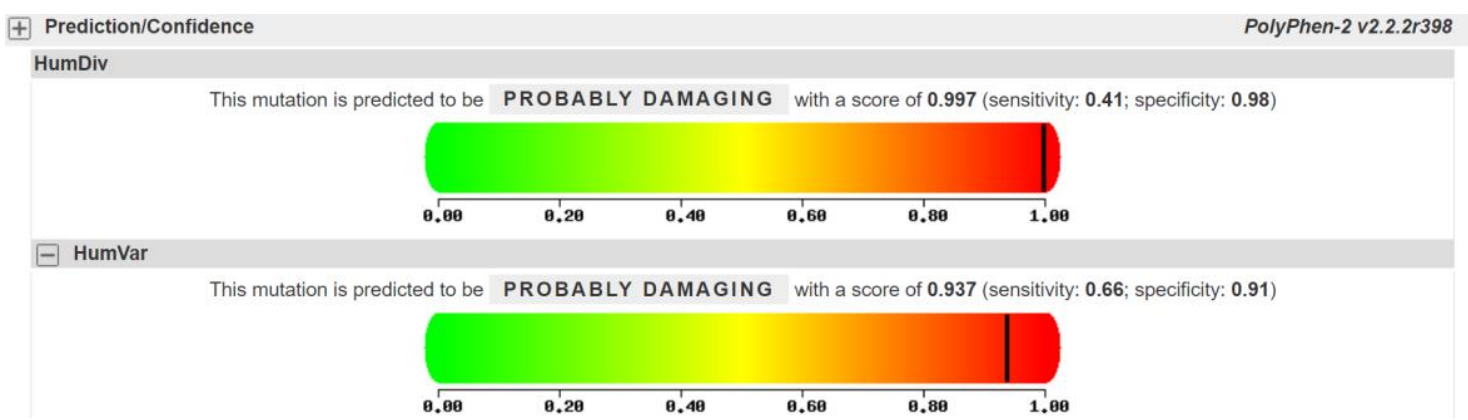

Figure 3. Polyphen-2 prediction of amino acid substitution caused by c.G589A/p.V197M (rs12329760)

Genetic variants of TMPRSS2 in the noncoding regions

Our study reveals a total of 29 variants in non-coding regions (Table 4). Two point mutations were identified in 5 ' untranslated region (UTR5), including c.-25G>A (rs890983082) and a novel variant c.$35 \mathrm{C}>\mathrm{T}$. We found 26 variants in introns, of which one relates to the deletion of an $\mathrm{A}$ nucleotide (rs542502939), one arises from the insertion of a sequence of nucleotides (rs112132031), one involves the deletion of two nucleotides (rs140530035), and the 
others occur through substitution. The frequency of each variant was calculated as shown in table 1. Variant rs140530035 shows the highest frequency (0.62222), followed by rs422471 (0.29444) and rs386416 (0.29259). The remaining mutations (rs141230106) were detected in 3' untranslated region (UTR3).

Table 4. Variants of TMPRSS2 in the non-coding regions

\begin{tabular}{|c|c|c|c|c|c|c|c|}
\hline \multirow[t]{2}{*}{ Region } & \multirow{2}{*}{$\begin{array}{l}\text { Location on } \\
\text { chromosome }\end{array}$} & \multirow{2}{*}{$\begin{array}{l}\text { Reference } \\
\text { SNP ID }\end{array}$} & \multirow{2}{*}{$\begin{array}{l}\text { Nucleotide } \\
\text { change }^{(*)}\end{array}$} & \multirow[t]{2}{*}{$\underset{(* *)}{\text { Frequency }}$} & \multirow{2}{*}{$\begin{array}{c}\text { Frequency } \\
\text { in this } \\
\text { study }\end{array}$} & \multicolumn{2}{|c|}{$\begin{array}{c}\text { Number of } \\
\text { subjects }\end{array}$} \\
\hline & & & & & & Het & Hom \\
\hline UTR5 & chr 21: 42879956 & rs890983082 & c. $-25 \mathrm{G}>\mathrm{A}$ & - & 0.00185 & 1 & 0 \\
\hline UTR5 & chr 21: 42879966 & unknown & c. $-35 \mathrm{C}>\mathrm{T}$ & - & 0.00185 & 1 & 0 \\
\hline intron & chr 21: 42838094 & rs542502939 & delA & - & 0.00185 & 1 & 0 \\
\hline intron & chr 21: 42838104 & rs118028230 & $\mathrm{G}>\mathrm{C}$ & 0.01877 & 0.12222 & 54 & 6 \\
\hline intron & chr 21: 42840172 & rs743542 & $\mathrm{G}>\mathrm{A}$ & 0.14936 & 0.00370 & 2 & 0 \\
\hline intron & chr 21: 42840187 & rs190618812 & $\mathrm{G}>\mathrm{A}$ & - & 0.00185 & 1 & 0 \\
\hline intron & chr 21: 42840580 & rs462321 & $\mathrm{T}>\mathrm{C}$ & 0.57808 & 0.01111 & 6 & 0 \\
\hline intron & chr 21: 42840595 & rs462326 & $\mathrm{G}>\mathrm{C}$ & 0.57308 & 0.00926 & 5 & 0 \\
\hline intron & chr 21: 42842713 & rs112132031 & $\begin{array}{c}\text { insCTAAGG } \\
\text { CCTCGGG }\end{array}$ & 0.82987 & 0.22963 & 38 & 43 \\
\hline intron & chr21: 42842771 & rs28524972 & $\mathrm{C}>\mathrm{G}$ & 0.28714 & 0.01111 & 6 & 0 \\
\hline intron & chr 21: 42843960 & rs464431 & $\mathrm{A}>\mathrm{G}$ & 0.87380 & 0.01667 & 5 & 2 \\
\hline intron & chr 21: 42845633 & rs2298660 & $\mathrm{C}>\mathrm{T}$ & 0.25859 & 0.08889 & 32 & 8 \\
\hline intron & chr 21: 42845638 & rs55964536 & $\mathrm{C}>\mathrm{T}$ & 0.24241 & 0.00185 & 1 & 0 \\
\hline intron & chr 21: 42845642 & rs2298661 & $\mathrm{C}>\mathrm{A}$ & 0.26777 & 0.12222 & 42 & 12 \\
\hline intron & $\begin{array}{c}\text { chr 21: } 42848561- \\
42848562\end{array}$ & rs 140530035 & $\operatorname{del} A G$ & 0.81330 & 0.62222 & 136 & 100 \\
\hline intron & chr 21: 42850911 & rs9974995 & $\mathrm{C}>\mathrm{T}$ & 0.26098 & 0.01111 & 6 & 0 \\
\hline intron & chr 21: 42850966 & rs73372193 & $\mathrm{A}>\mathrm{C}$ & 0.05611 & 0.01111 & 6 & 0 \\
\hline intron & chr 21: 42850977 & rs9974933 & $\mathrm{A}>\mathrm{G}$ & 0.26158 & 0.22963 & 108 & 8 \\
\hline intron & chr 21: 42851006 & rs9975014 & $A>G$ & 0.26238 & 0.23704 & 110 & 9 \\
\hline intron & chr 21: 42852591 & rs378501 & $\mathrm{A}>\mathrm{G}$ & - & 0.00370 & 2 & 0 \\
\hline intron & chr 21: 42860307 & rs422471 & $\mathrm{C}>\mathrm{T}$ & 0.55471 & 0.29444 & 129 & 15 \\
\hline intron & chr 21: 42860485 & rs386416 & $\mathrm{G}>\mathrm{C}$ & 0.55511 & 0.29259 & 128 & 15 \\
\hline intron & chr 21: 42860494 & rs3819138 & $\mathrm{C}>\mathrm{G}$ & 0.06849 & 0.05556 & 26 & 2 \\
\hline intron & chr 21: 42860593 & rs3787947 & $\mathrm{C}>\mathrm{T}$ & 0.30711 & 0.00556 & 3 & 0 \\
\hline intron & chr 21: 42861332 & rs429442 & $\mathrm{C}>\mathrm{T}$ & 0.27955 & 0.01111 & 6 & 0 \\
\hline intron & chr 21: 42869927 & rs181592444 & $\mathrm{C}>\mathrm{T}$ & 0.00220 & 0.00185 & 1 & 0 \\
\hline intron & chr 21: 42879724 & rs8126497 & $\mathrm{G}>\mathrm{A}$ & 0.10104 & 0.02222 & 12 & 0 \\
\hline intron & chr 21: 42879835 & rs951118351 & $\mathrm{C}>\mathrm{A}$ & - & 0.00370 & 2 & 0 \\
\hline UTR3 & chr 21: 42838004 & rs141230106 & c. $* 65 \mathrm{G}>\mathrm{A}$ & 0.0012 & 0.00370 & 2 & 0 \\
\hline
\end{tabular}

Notes: $(*)$ NM_001135099; (**) Frequency in "The 1000 genomes project 2015"; Hom: Homozygous; Het: Heterozygous; “"”: unknown.

\section{DISCUSSION}

Recently, Hou et al. (2020) highlighted that genetic variation in ACE2 or TMPRSS2 gene could personalize the treatment of people suffering from COVID-19. However, it might be difficult to directly disrupt ACE2 receptor in therapies because ACE2 serves as an essential regulator of heart function (Crackower et al., 2002). The absence of ACE2 activity in mice resulted in severe cardiac defects and an increase in angiotensin II levels. Meanwhile, TMPRSS2 mutant mice were normal and displayed no significant 
Nguyen Dang Ton et al.

abnormalities in organ histology and function (Kim et al., 2006). Consequently, TMPRSS2 protease could possibly be a promising candidate for development of treatments for COVID-19. Recently, a comparative study also reported that TMPRSS 2 gene might be a potential factor that guides the severity of the COVID-19 pandemic in the Italian population, which presented higher death rates and stratification in severity among sexes than East Asians (Asselta et al., 2020). Simultaneously, they found no strong evidence for the contribution of ACE2 in the severity of COVID-19. TMPRSS2 gene therefore was chosen for this polymorphic investigation.

Protease-dependent

SARS-CoV-2 infection as well as pathogenesis relies on endosomal cysteine proteases cathepsin $\mathrm{B}$ and $\mathrm{L}(\mathrm{Cat} / \mathrm{L})$ and TMPRSS2 protease (Hoffmann et al., 2020; Simmons et al., 2005; Shulla et al., 2011). The endosomal cysteine proteases-mediated entry requires acidic $\mathrm{pH}$. The inhibitors of endosomal acidification, for example, $\mathrm{NH}_{4} \mathrm{Cl}$ and bafilomycin $\mathrm{A} 1$, were demonstrated to be only effective for viral entry via $\mathrm{CatB} / \mathrm{L}$ pathway. Interestingly, these drugs might exert a negligible effect on patients with TMPRSS2 in wild-type form while $\mathrm{CatB} / \mathrm{L}$ protease is dispensable. As a result, in the treatment of COVID-19, drugs against endosomal acidification might be potential for patients carrying missense TMPRSS2 variants rather than patients with wild-type phenotype.

In the current study, nearly half of all subjects possess p.V197M (rs 12329760) variant that was proposed to be damaging by bioinformatics tools. TMPRSS2 rs 12329760 variant was remarkably related to genomic rearrangements pertaining to TMPRSS2, which leads to the risk of prostate cancer (FitzGerald et al., 2008). Moreover, this group of researchers also showed rs12329760 mutation in another reference sequence (p.V160M) to be highly conserved among mammals. This missense variant is located in an exonic splicing enhancer srp40 site. Additionally, A allele is proposed to interrupt this exonic splicing enhancer, resulting in the possibility of exon skipping or protein malformation.

In conclusion, our study identified a total of 43 variants of the TMPRSS2 gene in 270 Vietnamese's WES data. Variants found in coding regions included seven synonymous and seven non-synonymous point mutations, of which one was a novel mutation (c.A1336C/p.R446R). Variant c.G589A/p.V197M (rs12329760) possesses the highest frequency and was predicted to have the ability to damage protein by SIFT and Polyphen-2.

\section{REFERENCES}

Asselta R., Paraboschi E. M., Mantovani A., Duga S., 2020. ACE2 and TMPRSS2 variants and expression as candidates to sex and country differences in COVID-19 severity in Italy. Aging (Albany. NY)., 12(11): 10087-10098.

Baughn L. B., Sharma N., Elhaik E., Sekulic A., Bryce A. H., Fonseca R., 2020. Targeting TMPRSS2 in SARS-CoV-2 Infection. Mayo Clin. Proc., 95(9): 1989-1999.

Chan J. F.-W., Yuan S., Kok K.-H., To K. K.W., Chu H., Yang J., Xing F., Liu J., Yip C. C.-Y., Poon R. W.-S., Tsoi H.-W., Lo S. K.-F., Chan K.-H., Poon V. K.-M., Chan W.-M., Ip J. D., Cai J.-P., Cheng V. C.-C., Chen H., Hui C. K.-M., Yuen K.Y., 2020. A familial cluster of pneumonia associated with the 2019 novel coronavirus indicating person-to-person transmission: a study of a family cluster. Lancet, 395(10223): 514-523.

Crackower M. A., Sarao R., Oliveira-dosSantos A. J., Da Costa J., Zhang L., 2002. Angiotensin-converting enzyme 2 is an essential regulator of heart function. Nature, 417(6891): 822-828.

De Almeida-Pititto B., Dualib P. M., Zajdenverg L., Dantas J. R., De Souza F. D., Rodacki M., Bertoluci M. C., 2020. Severity and mortality of COVID 19 in patients with diabetes, hypertension and 
cardiovascular disease: A meta-analysis. Diabetol. Metab. Syndr., 12(1): 75.

Dong Y., Dong Y., Mo X., Hu Y., Qi X., Jiang F., Jiang Z., Jiang Z., Tong S., Tong S., Tong S., 2020. Epidemiology of COVID-19 among children in China. Pediatrics. https://doi.org/10.1542/peds. 2020-0702

FitzGerald L. M., Agalliu I., Johnson K., Miller M. A., Kwon E. M., Hurtado-Coll A., Fazli L., Rajput A. B., Gleave M. E., Cox M. E., Ostrander E. A., Stanford J. L., Huntsman D. G., 2008. Association of TMPRSS2-ERG gene fusion with clinical characteristics and outcomes: Results from a population-based study of prostate cancer. BMC Cancer, 8 . https://doi.org/10.1186/1471-2407-8-230

Gorbalenya A., Baker S., Baric R., de Groot R., Drosten C., Gulyaeva A., Haagmans B., Lauber C., Leontovich A., Neuman B., Penzar D., Perlman S., Poon L., Samborskiy D., Sidorov I., Sola I., Ziebuhr J., 2020. Severe acute respiratory syndrome-related coronavirus: The species and its viruses - a statement of the Coronavirus Study Group. Nat. Microbiol., https://doi.org/10.1101/2020. 02.07.937862

Gross C. P., Essien U. R., Pasha S., Gross J. R., Wang S. yi, Nunez-Smith M., 2020. Racial and Ethnic Disparities in Population-Level Covid-19 Mortality. J. Gen. Intern. Med., 35(10): 3097-3099.

Hatcher S. M., Agnew-Brune C., Anderson M., Zambrano L. D., Rose C. E., Jim M. A., Baugher A., Liu G. S., Patel S. V., Evans M. E., Pindyck T., Dubray C. L., Rainey J. J., Chen J., Sadowski C., Winglee K., Penman-Aguilar A., Dixit A., Claw E., Parshall C., Provost E., Ayala A., Gonzalez G., Ritchey J., Davis J., Warren-Mears V., Joshi S., Weiser T., Echo-Hawk A., Dominguez A., Poel A., Duke C., Ransby I., Apostolou A., McCollum J., 2020. COVID-19 Among American Indian and Alaska Native Persons - 23 States, January 31-July 3,
2020. MMWR. Morb. Mortal. Wkly. Rep., 69(34): 1166-1169.

Hoffmann M., Kleine-Weber H., Schroeder S., Krüger N., Herrler T., Erichsen S., Schiergens T. S., Herrler G., Wu N. H., Nitsche A., Müller M. A., Drosten C., Pöhlmann S., 2020. SARS-CoV-2 Cell Entry Depends on ACE2 and TMPRSS2 and Is Blocked by a Clinically Proven Protease Inhibitor. Cell, 181(2): 271-280.e8.

Hou Y., Zhao J., Martin W., Kallianpur A., Chung M. K., Jehi L., Sharifi N., Erzurum S., Eng C., Cheng F., 2020. New insights into genetic susceptibility of COVID-19: An ACE2 and TMPRSS2 polymorphism analysis. BMC Med., 18(1).

Kim T. S., Heinlein C., Hackman R. C., Nelson P. S., 2006. Phenotypic Analysis of Mice Lacking the Tmprss2-Encoded Protease. Mol. Cell. Biol., 26(3): 965-975.

Kuhn J. H., Li W., Choe H., Farzan M., 2004., November Angiotensin-converting enzyme 2: A functional receptor for SARS coronavirus. Cell. Mol. Life Sci. https://doi.org/10.1007/s00018-004-4242-5

Kyte J., Doolittle R. F., 1982. A simple method for displaying the hydropathic character of a protein. J. Mol. Biol., 157(1): 105-132.

Li W., Moore M. J., Vasllieva N., Sui J., Wong S. K., Berne M. A., Somasundaran M., Sullivan J. L., Luzuriaga K., Greeneugh T. C., Choe H., Farzan M., 2003. Angiotensin-converting enzyme 2 is a functional receptor for the SARS coronavirus. Nature, 426(6965): 450-454.

Shulla A., Heald-Sargent T., Subramanya G., Zhao J., Perlman S., Gallagher T., 2011. A Transmembrane Serine Protease Is Linked to the Severe Acute Respiratory Syndrome Coronavirus Receptor and Activates Virus Entry. J. Virol., 85(2): 873-882.

Simmons G., Gosalia D. N., Rennekamp A. J., Reeves J. D., Diamond S. L., Bates P., 2005. Inhibitors of cathepsin L prevent severe acute respiratory syndrome 
coronavirus entry. Proc. Natl. Acad. Sci. U. S. A., 102(33): 11876-11881.

Torre-Fuentes L., Matías-Guiu J., HernándezLorenzo L., Montero-Escribano P., Pytel V., Porta-Etessam J., Gómez-Pinedo U., Matías-Guiu J. A., 2020. ACE2, TMPRSS2, and Furin variants and SARSCoV-2 infection in Madrid, Spain. J. Med. Virol., 93(2): 863-869.

Walls A. C., Park Y. J., Tortorici M. A., Wall A., McGuire A. T., Veesler D., 2020. Structure, Function, and Antigenicity of the SARS-CoV-2 Spike Glycoprotein. Cell, 181(2): 281-292.e6.

Wang C., Horby P. W., Hayden F. G., Gao G. F., 2020. A novel coronavirus outbreak of global health concern. Lancet. https://doi.org/10.1016/S0140-6736(20)30 185-9
WHO Director-General's remarks at the media briefing on 2019-nCoV on 11 February 2020. https://www.who.int/dg/speeches/detail/w ho-director-general-s-remarks-at-themedia-briefing-on-2019-ncov-on-11february-2020 (accessed 4 December 2020)

Wu C., Zheng M., Yang Y., Gu X., Yang K., Li M., Liu Y., Zhang Q., Zhang P., Wang Y., Wang Q., Xu Y., Zhou Y., Zhang Y., Chen L., Li H., 2020. Furin: A Potential Therapeutic Target for COVID-19. IScience, 23(10): 101642.

Zhu N., Zhang D., Wang W., Li X., Yang B., Song J., Zhao X., Huang B., Shi W., Lu R., Niu P., Zhan F., Ma X., Wang D., Xu W., Wu G., Gao G. F., Tan W., 2020. A Novel Coronavirus from Patients with Pneumonia in China, 2019. N. Engl. J. Med., 382(8): 727-733. 